\title{
Perforation of the greater gastric curvature by a gastric adenocarcinoma with engulfment of the upper pole of the spleen
}
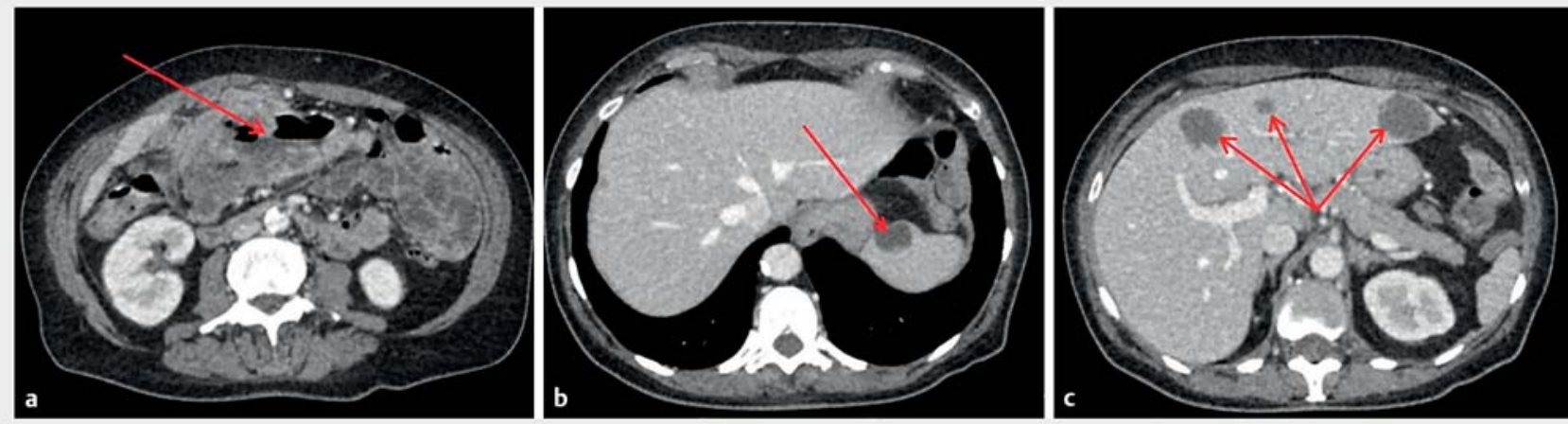

Fig. 1 Abdominal and pelvic computed tomography scan performed before oeso-gastro-duodenal endoscopy. a Arrowhead showing the gastric lesion in the pyloric region. b Arrowhead showing secondary splenic lesion. c Arrowheads showing secondary liver lesions.

Perforated gastric cancer is a rare condition [1]. It has an extremely poor prognosis. There are few data in the literature regarding perforated gastric adenocarcinoma involving the spleen [2]. We report here the case of a 66-year-old woman who was admitted to our department with general deterioration, right hypochondrium pain, and anemia of $7.5 \mathrm{~g} / \mathrm{dl}$. An abdominal and pelvic computed tomography was performed, revealing a large necrotic mass with irregular contours of the greater curvature of the stomach, measuring $10.3 \times 5.7 \mathrm{~cm}$, and multiple coliomesenteric, epiploic, and retroperitoneal (left lateral renal) lymph nodes. Three hypodense irregularly contoured hepatic nodules in segment IV and in the left liver were found as well, highly suspicious of secondary locations given the context. There was also a cystic splenic nodule, suspected of being a metastatic lesion ( $>$ Fig. 1).

An oeso-gastro-duodenal endoscopy was performed under general anesthesia. A blocked gastric perforation (of almost the whole greater curvature) was found at the lower part of the fundus and at the antrum. Inside the cavity, fibrinous debris and the upper pole of the spleen were found ( Video 1 ). Cautious biopsies were performed.

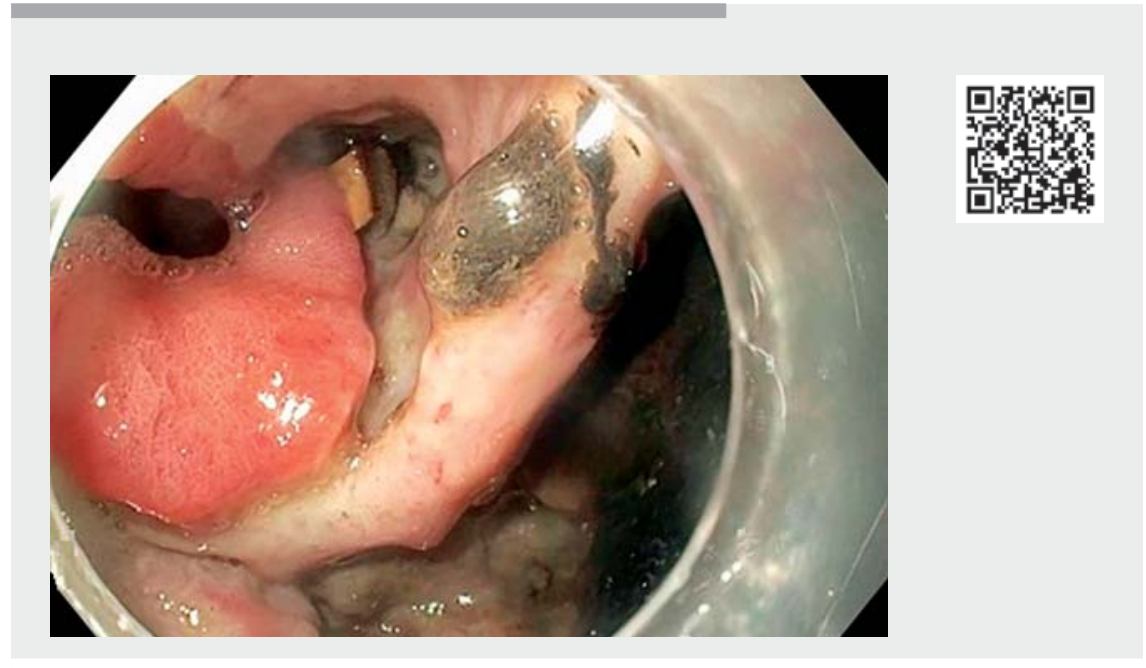

Video 1 Diagnostic gastroscopy of gastric adenocarcinoma with perforation and envelopment of the upper pole of the spleen.

Histological examination revealed a very superficial gastric mucosa, with no muscularis mucosa, partly occupied by structures of a poorly differentiated neoplasm. On immunohistochemistry, the neoplastic cells had an epithelial phenotype, and antibodies directed against pankeratin AE1/AE3 and keratin 7 were positive. Carcinoma cells were negative for $\mathrm{Cdx} 2$ and HER2 ( Fig. 2, > Fig.3).
Perforated gastric cancer does not appear in the literature to alter the oncological prognosis if it is treated with two-step surgery [1,3]. In this case of advanced perforating and metastatic disease, only palliative treatment was considered after discussion in a multidisciplinary team meeting.

Endoscopy_UCTN_Code_CCL_1AB_2AD_3AB 

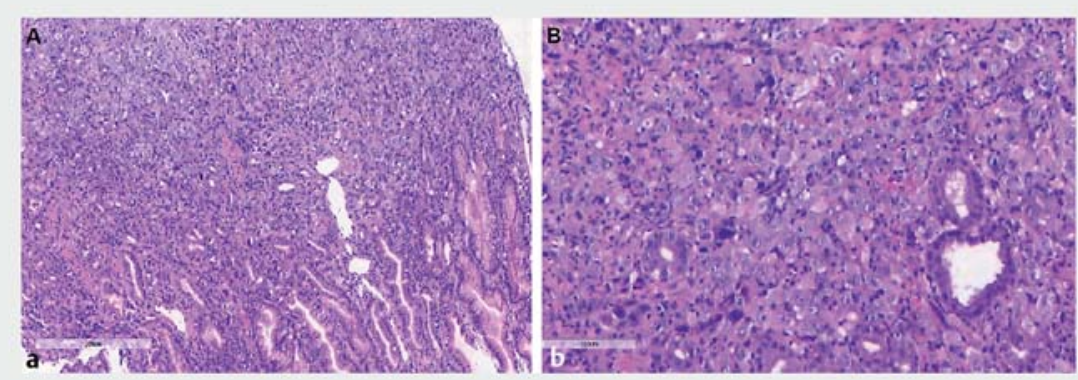

Fig. 2 Histological section of the gastric biopsies, hematoxylin-eosin stain. a Gastric mucosa infiltrated by adenocarcinoma, magnification $\times 5$. $\mathbf{b}$ Adenocarcinoma cells: poorly differentiated appearance, cells in trabeculae or clumps, no glandular formation (the glands visible are those of the residual mucosa); magnification $\times 20$.
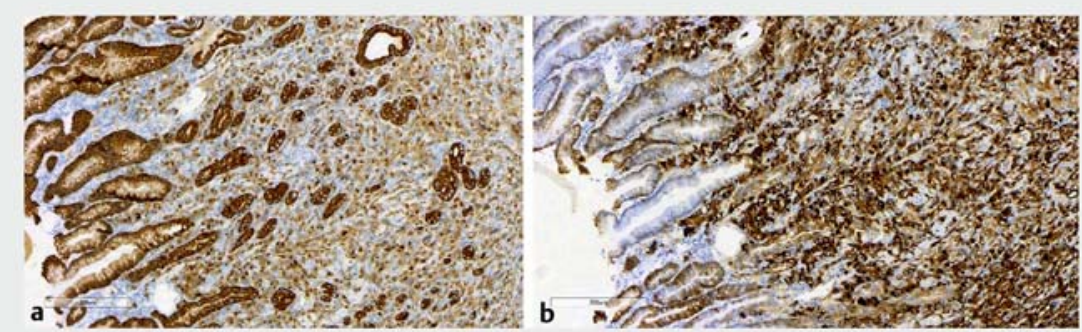

- Fig. 3 Immunostaining on gastric biopsies. a Immunostaining for anti-pankeratin antibody: strong labeling of normal glands, weaker labeling of adenocarcinoma cells; magnification $\times 10$. $\mathbf{b}$ Immunostaining for anti-keratin 7 antibody: strong labeling of adenocarcinoma cells (in favor of upper digestive origin of adenocarcinoma); magnification $\times 10$.

\section{Acknowledgement}

This work was supported by French state funds managed within the "Plan Investissements d'Avenir" and by the ANR (reference ANR-10-IAHU-02).

\section{Competing interests}

The authors declare that they have no conflict of interest.

The authors

Pierre Mayer ${ }^{1,2}$, Lucile Héroin ${ }^{1,2} థ$ Didier Mutter ${ }^{2,3}$, Laetitia Oertel ${ }^{4}$, Mathieu Pioche $^{5}$, François Habersetzer ${ }^{1,2}$, Guillaume Philouze $^{2,3}$

1 Department of Hepatology and Gastroenterology, Pôle Hépato-digestif, Nouvel Hôpital Civil, Hôpitaux Universitaires de Strasbourg (HUS), Strasbourg, France
2 IHU-Strasbourg (Institut HospitaloUniversitaire), Strasbourg, France

3 Department of Visceral and Digestive Surgery, Pôle Hépato-digestif, Nouvel Hôpital Civil, HUS, Strasbourg, France

4 Department of Pathology, HUS, Strasbourg, France

5 Department of Endoscopy and Hepatogastroenterology, Pavillon L, Edouard Herriot Hospital, Lyon, France

\section{Corresponding author}

\section{Pierre Mayer, MD}

Department of Hepatology and Gastroenterology, Pôle Hépato-digestif, Nouvel Hôpital Civil, Hôpitaux Universitaires de Strasbourg, 1, place de l'hôpital, 67000 Strasbourg, France pierre-emmanuel.mayer@chru-strasbourg.fr

\section{References}

[1] Mahar AL, Brar SS, Coburn NG et al. Surgical management of gastric perforation in the setting of gastric cancer. Gastric Cancer 2012; 15 (Suppl. 01): S146-S152. doi:10.1007/s10120-011-0095-4

[2] Gonçalves R, Saad R, Malheiros CA et al. Gastric cancer with lesion extending to spleen and perforation into free peritoneum. Rev Assoc Med Bras (1992) 2017; 63: 484-487. doi:10.1590/18069282.63.06.484

[3] Wang S-Y, Hsu C-H, Liao C-H et al. Surgical outcome evaluation of perforated gastric cancer: from the aspects of both acute care surgery and surgical oncology. Scand J Gastroenterol 2017; 52: 1371-1376. doi:10.1080/00365521.2017.1369562

Bibliography

Endoscopy 2022; 54: E680-E681

DOI 10.1055/a-1743-1628

ISSN 0013-726X

published online 18.2.2022

(c) 2022. Thieme. All rights reserved. Georg Thieme Verlag KG, Rüdigerstraße 14, 70469 Stuttgart, Germany

\section{ENDOSCOPY E-VIDEOS}

https://eref.thieme.de/e-videos

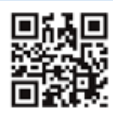

Endoscopy E-Videos is an open access online section, reporting on interesting cases and new techniques in gastroenterological endoscopy. All papers include a high quality video and all contributions are freely accessible online. Processing charges apply (currently EUR 375), discounts and wavers acc. to HINARI are available.

This section has its own submission website at

https://mc.manuscriptcentral.com/e-videos 